\title{
Evaluation of Risk Factors for Prolonged Stay in Post Anaesthesia Care Unit (PACU) in a Tertiary Care Hospital of Saudia Arabia
}

\author{
Dr Anwar ul Huda ${ }^{*}$, Dr Nasrullah Sheikh ${ }^{2}$ \\ ${ }^{I}$ Consultant, Department of Anaesthesia, Security Forces Hospital Program, Malaz, Riyadh, Kingdom \\ of Saudi Arabia, ${ }^{2}$ Senior registrar, Department of Anaesthesia \\ Security Forces Hospital Program, Malaz, Riyadh, Kingdom of Saudi Arabia
}

\begin{abstract}
Background
Delayed discharges and transfers from PACU result in congestion and bottleneck at various stages along perioperative care. We did this retrospective cross-sectional study to evaluate the incidence and risk factors for prolonged length of stay (LOS) in PACU. This study was conducted at Security Forces Hospital, Riyadh, Kingdom of Saudi Arabia
\end{abstract}

\begin{abstract}
Materials and methods
We included patients who stayed postoperatively in PACU for more than 2 hours. We collected the data of patients having surgical procedures in main operation room from April 2019 to February 2020. We collected preoperative, operative and postoperative variables of all included patients. The reasons for prolonged LOS in PACU were recorded as documented in patient notes.
\end{abstract}

\section{Results}

There was a total of 206 prolonged stays in PACU of our hospital. Perioperative cardiovascular and respiratory adverse events accounted for most of cases of prolonged PACU stays followed by surgical reasons like bleeding and extended surgery.

\section{Conclusion}

The main reasons for prolonged stay in PACU were cardiovascular and respiratory adverse events in perioperative period.

Key words: prolonged length of stay, post anaesthesia care unit (PACU), adverse events

\section{Introduction}

Post anesthesia care unit (PACU) requires expenses in terms of space, personnel and equipment. The numbers of nurses and doctors and nurse to patient ratio determines the personnel cost. The level of routine monitoring required affects the capital expenses for equipment and operating expenses for disposables. By reducing the recovery times in PACU, these expenses can significantly be reduced. ${ }^{1,2}$

PACU length of stay (LOS) is considered as a clinical indicator and usually 2 hours are taken

*Correspondence : Anwar ul Huda

E mail: hudaanwar90@yahoo.com

iD https://orcid.org/009665026654719

Received: 03/07/2020

Accepted: 26/03/2021

DOI: http:/doi.org/10.4038/slja.v29i1.8631 as benchmark time because studies have shown that patients achieve a satisfactory discharge score during $1^{\text {st }}$ two hours of postoperative period in majority of cases. ${ }^{3}$

Seago et al in an observational study mentioned risk factors for prolonged LOS in PACU which included age, use of pain medications in PACU, duration of surgery, respiratory, cardiovascular and pain responses in postoperative period. Organizational factors were also important predictors in the study. ${ }^{4}$ Samad et $a^{5}$ showed major reason for prolonged stay as need for postoperative monitoring followed by unavailability of special care beds, pain management, delayed recovery from regional block and unplanned postoperative ventilation. The objective of this study was to evaluate the incidence and risk factors for prolonged LOS in PACU.

\section{Materials and methods}

We conducted a retrospective cross-sectional study at a tertiary care hospital in Riyadh, Saudia Arabia. We included patients who stayed 
postoperatively in PACU for more than 2 hours. We excluded patients who bypassed the PACU, or who were operated in surgical day care and obstetric suite. We collected the data of patients having surgical procedures in main operation room from April 2019 to February 2020. We collected preoperative, operative and postoperative variables of patients who stayed in PACU for more than 2 hours. The reasons for prolonged LOS in PACU were recorded as documented in patient notes. We collected preoperative variables including age, gender, type of surgery, presence of medical diseases like hypertension, diabetes, ischemic heart disease, respiratory disease, renal dysfunction and neurological problems etc. Operative variables like type of surgery, occurrence of any intraoperative complications or adverse events related to anesthesia or surgery were recorded. We also collected postoperative variables like unplanned ward or ICU admission, occurrence of any airway, respiratory, cardiovascular and or neurological events and level of pain control and presence of PONV.

\section{Results}

During the study period, there were a total of 7985 surgical procedures performed with 206 $(2.58 \%)$ prolonged stays in PACU in our hospital. $94(46 \%)$ of these stays occurred after high risk surgeries, $110(53 \%)$ after intermediate risk surgeries and $2(1 \%)$ after low risk surgery. Regarding co-morbidities, 21 (10\%) occurred in ASA 1, $113(55 \%)$ in ASA 2, $61(30 \%)$ in ASA 3 and $11(5.3 \%)$ in ASA 4 cases. The distribution of the cases among different specialities were as follow; 67 (32.5\%) general surgery, $39(19 \%)$ orthopaedics, $32(15.5 \%)$ obstetrics, 28 (13.6\%) urology, 14 (6.7\%) neurosurgery, $11(5.3 \%)$ gynaecology, $7(3.3 \%)$ vascular, $4(1.9 \%)$ thoracic, $2(0.9 \%), 2(0.9 \%)$ plastics and $2(0.9 \%)$ faciomaxillary surgery. Out of 206, 134 (65\%) prolonged stays happened after GA only, 5 (2.4\%) after GA with neuraxial block, 19 (9.2\%) after GA with regional blocks, $41(20 \%)$ after neuraxial block, $6(3 \%)$ after regional block only and $1(0.5 \%)$ after sedation. The reasons for prolonged PACU stays are detailed in table 1 .

There was a total of $55(26 \%)$ intraoperative and $140(68 \%)$ postoperative adverse events and 11 (5\%) administrative/ nonclinical reasons which resulted in prolonged PACU stays.
Table 1

Reasons for prolonged PACU stay

\begin{tabular}{|c|c|}
\hline Reasons for prolonged PACU stay & $\begin{array}{l}\text { Number } \\
(\%)\end{array}$ \\
\hline $\begin{array}{l}\text { Cardiovascular } \\
\text { Postoperative hypotension/ tachycardia } \\
\text { Postoperative hypertension } \\
\text { Postoperative chest pain } \\
\text { Intraoperative hypotension/tachycardia }\end{array}$ & $\begin{array}{l}46(22.33) \\
5(2.4) \\
1(0.5) \\
1(0.5)\end{array}$ \\
\hline $\begin{array}{l}\text { Respiratory } \\
\text { Postoperative respiratory/airway event } \\
\text { Intraoperative respiratory event (Bronchospasm) } \\
\text { Intraoperative airway event (Laryngospasm at } \\
\text { extubation) } \\
\text { Difficult intubation }\end{array}$ & $\begin{array}{l}25(12.1) \\
2(1) \\
2(1) \\
1(0.5)\end{array}$ \\
\hline $\begin{array}{l}\text { Neurological } \\
\text { Postoperative confusion/restlessness } \\
\text { Late recovery from spinal } \\
\text { Need for neurological monitoring } \\
\text { Postoperative seizure }\end{array}$ & $\begin{array}{l}4(0.4) \\
3(1.45) \\
2(1) \\
1(0.5)\end{array}$ \\
\hline $\begin{array}{l}\text { Surgical reasons } \\
\text { Postoperative bleeding/transfusion } \\
\text { Extended surgery } \\
\text { Other Surgical reasons (eg. Surgeon request, } \\
\text { Surgeon unavailability to assess in recovery, } \\
\text { delay in receiving Injection Mitomycin) } \\
\text { Intraoperative bleeding }\end{array}$ & $\begin{array}{l}26(12.6) \\
26(12.6) \\
7(3.4) \\
7(3.4)\end{array}$ \\
\hline Postoperative pain & $16(7.8)$ \\
\hline Perioperative Sepsis & $7(3.4)$ \\
\hline Perioperative allergy/anaphylaxis & $4(1.9)$ \\
\hline Hypothermia & $9(4.4)$ \\
\hline $\begin{array}{l}\text { Non-medical reasons (Availability of } \\
\text { bed/drugs/doctor/porter) }\end{array}$ & $8(3.9)$ \\
\hline TURP syndrome & $2(1)$ \\
\hline Surgeon request & $1(0.5)$ \\
\hline
\end{tabular}

\section{Graph 1}

Distribution of events among different surgical specialities

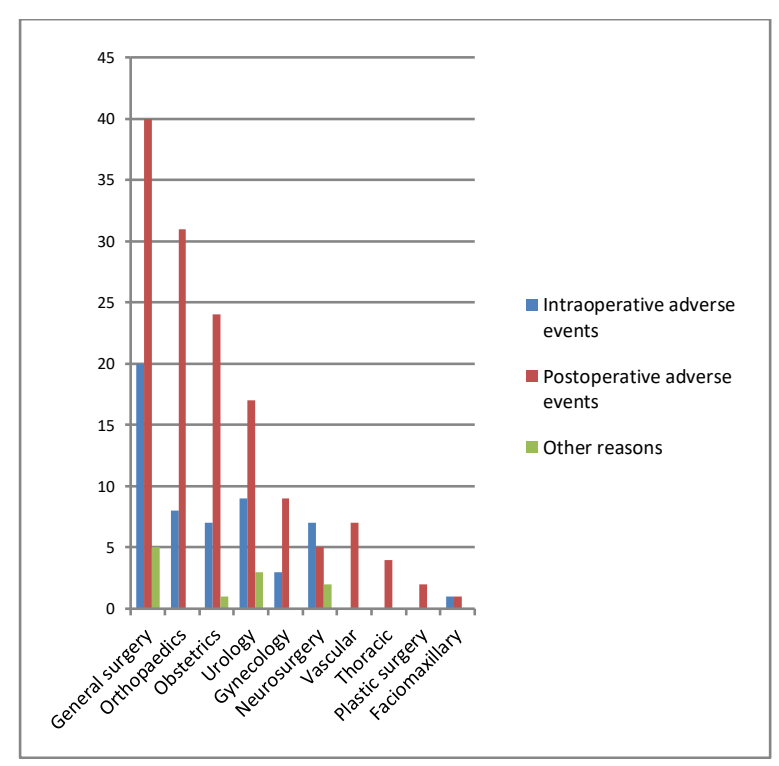


The distribution of these reasons among different specialities is mentioned in graph 1 .

Among 55 intraoperative adverse events, there were $26(47.2 \%)$ extended surgeries, $8(14.5 \%)$ intraoperative bleeding and $7(12.7 \%)$ other surgical reasons intraoperatively. There were 5 (0.9\%) airway/respiratory adverse events including one difficult intubation. There were 4 $(7.2 \%)$ episodes of developing sepsis intraoperatively. There were $2(0.4 \%)$ TURP syndromes resulting in delayed discharges from PACU. Also, there were 2 (0.4\%) allergy/anaphylaxes and one intraoperative hypotension/tachycardia which resulted in prolonged PACU stay. Out of these 55 intraoperative adverse events, 21 (38\%) occurred in intermediate risk surgeries and 34 $(62 \%)$ in high risk surgeries. The distribution of intraoperative adverse events in different ASA classes is mentioned in graph 2. Forty-five $(81.8 \%)$ events occurred in patients having GA and $10(18.2 \%)$ in neuraxial block. All 5 airway/respiratory events occurred in patients having GA. Out of 8 intraoperative bleeding, 4 were in obstetrics, 3 in gynaecology and 1 in orthopaedics surgery.

\section{Graph 2}

Distribution of intraoperative adverse events in different ASA class

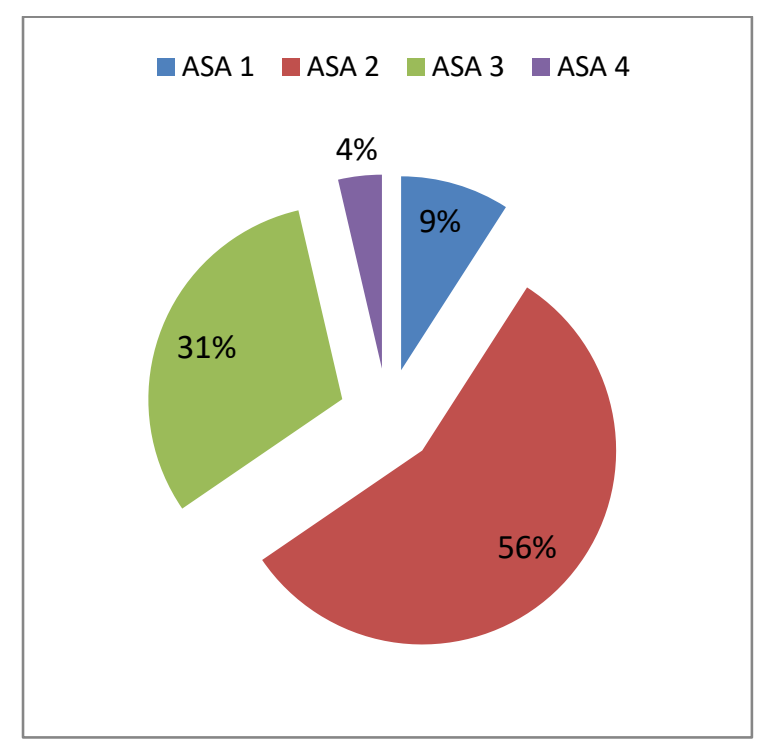

There were 140 postoperative adverse events. Among those, there were 36 (25.7\%) cases with postoperative hypotension/ tachycardia. Five patients had high blood pressure in PACU and needed prolonged stay. Also, one patient developed chest pain and had to stay longer while ongoing evaluation was being carried out. There were $25(17.8 \%)$ postoperative adverse events related to airway/respiratory problems. There were 26 (18.5\%) patients who either had new bleeding postoperatively or were observed for bleeding in PACU and needed blood transfusion in PACU. $16(11.4 \%)$ patients needed pain management which resulted in prolonged PACU stay. $9(6.4 \%)$ patients developed hypothermia which needed prolonged stay in PACU. $4(2.8 \%)$ patients stayed longer because of late recovery from spinal, while 4 (2.8\%) developed postoperative restlessness / confusion. One patient had postoperative seizure. 2 patients had postoperative allergy/anaphylaxis. There were 12 (8.5\%) patients who waited for ICU evaluation and later admission. Among those, 8 patients had postoperative hypotension/tachycardia and $2 \mathrm{had}$ intraoperative respiratory problems. Additionally, there were 11 patients who had prolonged PACU stay due to some administrative or non-clinical reasons. Among those, 2 needed close neurological monitoring for early postoperative period and there was no ICU bed available. One patient stayed longer because surgeon requested. There were 8 cases with non-clinical reasons among those 6 were due to ward bed unavailability.

Among 36 postoperative hypotension / tachycardia, 14 occurred after intermediate risk surgeries and 14 after high risk surgeries. 22 out of these 36 hypotension/tachycardia cases were known hypertensive and 9 had ischemic heart diseases. Among 25 respiratory/airway events postoperatively, 17 occurred in patients with respiratory diseases. 16 out of 17 respiratory/airway adverse events occurred after GA. Among 26 cases of postoperative bleeding/blood transfusion, 12 were from obstetrics, 5 from gynaecology, 3 from urology, 3 from General surgery, 2 from orthopaedics and one from Faciomaxillary. Among 9 cases of postoperative hypothermia, 6 occurred after high risk surgeries and 3 after intermediate risk surgeries. Among 12 cases who needed ICU evaluation postoperatively, 5 were after orthopaedics surgery, 2 after general surgery, 2 after neurosurgery, 1 each after vascular, plastic and urology surgery. Among these cases, 4 were classified preoperatively as ASA 2, 5 as ASA 3 and 3 as ASA 4. There was a total of 14 
unplanned ward admissions postoperatively. Among those, 5 were because of the need for pain management, 3 because of surgical complications, 2 because of perioperative sepsis, 1 hypothermia, 1 because of unstable haemodynamics, 1 because of respiratory problems, and one because of postoperative confusion.

\section{Discussion}

Delayed discharges and transfers result in congestion and bottleneck at various stages along perioperative care. ${ }^{6}$ In our study, we found the incidence of prolonged PACU stays as 2.58 $\%$ which is much lower than reported by Samad et al ${ }^{5}$ as $8.1 \%$. Mann-Farrar et al concluded that patients having prolonged stays in PACU due to clinical reasons tend to develop clinical deterioration in ward more frequently than patients with routine PACU stay. Also, prolonged PACU stay happened more in patients who were older, had high ASA, and were discharged later in the day. ${ }^{7}$ Rose et al showed that preoperative factors like age $>60$ years, male gender, diabetes and obesity, and operative factors like emergency surgery and surgery with longer duration ( $>4$ hours), resulted in increased risk of critical respiratory events, longer PACU stay and more cardiac related problems. ${ }^{8,9} \mathrm{~A}$ retrospective analysis by Toby et $\mathrm{al}^{10}$ revealed PONV as the most common event associated with prolonged PACU stay. History of hypertension and the need for antihypertensive medication in PACU were also important reasons for prolonged PACU stays. In our study, we also noticed that occurrence of postoperative cardiovascular adverse events was more common in patients with history of hypertension. Although in our study, none of the patients stayed longer because of PONV and or its management. Our study revealed that perioperative cardiovascular and respiratory/ airway events account for significant percentage $(40.33 \%)$ of prolonged PACU stay. Surgical reasons were the second most common reason as $32 \%$ of total prolonged PACU stay. Nonmedical reasons or administrative reasons were accounted for only 8 cases in our study which was not consistent with findings by Samad et $\mathrm{al}^{5}$ and Cowie el al. ${ }^{11}$ Cowie et $\mathrm{al}^{11}$ in their study mentioned that the most common reasons for prolonged stay in PACU were non-availability of ward bed followed by non- availability of PACU nurses and ward nurses. We will recommend to improve communication among different specialities to reduce prolonged PACU stays and unplanned ward admissions. It is also essential to plan postoperative care for patients who are considered at higher risk of prolonged PACU stay based on our study. Limitations of the study include retrospective study and small sample size.

\section{Conclusion}

Perioperative cardiovascular and respiratory adverse events are the major reasons for prolonged stay in PACU.

\section{Conflict of interest}

None

No disclosure

No funding

\section{References}

1. Barash PG, Cullen BF, Stoelting RK: Clinical Anesthesia, 3rd edition. Philadelphia, LippincottRaven Publishers, 1997, pp 1279.

2. Dexter F, Tinker JH. Analysis of strategies to decrease post anaesthesia care unit costs. Anesthesiology. 1995; 82(1): 94-101.

3. Chung F. Recovery pattern and home readiness after ambulatory surgery. Anesth Analg 1995; 80: 896-902.

4. Seago JA, Weitz S, Walczak S. Factors influencing stay in the postanesthesia care unit: a prospective analysis. J-Clin-Anesth 1998; 10: 579-87.

5. Samad K, Khan M, Saleemullah H, Khan FA et al. Unplanned prolonged postanesthesia care unit length of stay and factors affecting it. J Pak Med Assoc. 2006; 3: 108-112.

6. Weissman C. The enhanced postoperative care system. J Clin Anesth. 2005; 17: 314- 322.

7. Mann-Farrar J, Egan E, Higgins A, Wysocki L et al. Are Postoperative Clinical Outcomes Influenced by Length of Stay in the Postanesthesia Care Unit? J Perianesth Nurs. 2019 Apr; 34(2): 386-393. https://doi:10.1016/j.jopan.2018.07.004

8. Rose DK, Cohen MM, Wigglesworth DF, DeBoer DP: Critical respiratory events in the postanesthesia care unit. Patient, surgical, and anesthetic factors. Anesthesiology 1994; 81:4108.

9. Rose DK, Cohen MM, DeBoer DP: Cardiovascular events in the postanesthesia care unit: contribution of risk factors. Anesthesiology 1996; 84: 772-81.

10. Weingarten TN, Hawkins NM, Beam WB, et al. Factors associated with prolonged anesthesia recovery following laparoscopic bariatric surgery: a retrospective analysis. Obs Surg. 2015; 25(6): 1024-1030. 
Huda et al. Sri Lankan Journal of Anaesthesiology: 29(1): 29-33 (2021)

https://doi:10.1007/s11695-014-1468-7

11. Cowie B, Corcoran P. Postanesthesia care unit discharge delay for nonclinical reasons. $J$ Perianesth Nurs. 2012 Dec; 27(6); 393-8.

https://doi:10.1016/j.jopan.2012.05.013 